\title{
The effects of formal and acoustic repetition in the Brown-Peterson paradigm*
}

\author{
DELOS D. WICKENS and JOYCE J. CONTRUCCI $\dagger$ \\ Ohio State University, Columbus, Ohio 43210
}

\begin{abstract}
On a given trial in the Peterson and Peterson paradigm, the trigram $B, K, T$ was presented. For one group this same trigram had been presented three trials earlier (exact repetition). For another group the critical item which had preceded the consonant trigram was BEE, KAY, TEA (homophonic repetition). Both groups showed a repetition facilitation significant beyond that of the appropriate control groups. The exact repetition group excelled the homophonic repetition group. Postexperimental questionnaires on awareness of the experimental manipulation did not precisely clarify the results obtained. The data support the view of multiple encoding.
\end{abstract}

It has been shown by Cermak $(1969,1970)$ that, if in the Brown-Peterson paradigm the homonyms of a word triad are repeated on the next trial, there is a marked facilitation of performance on that "repeat" trial. It is apparent that data of these sorts are consonant with an attribute interpretation of the memory process (Underwood, 1969). If we assume that words are encoded in multiple component fashion (Wickens, 1970) involving, at the minimum, a semantic and an acoustic component, then the reoccurrence of either component on a subsequent trial should result in recall enhancement through whatever mechanism is responsible for the well known effect of repetition. ${ }^{1}$

The present experiment extends the Cermak work in several important ways. In a recall task where performance is measured in terms of percent correct, it is essential to know exactly what Ss are recalling on each trial. Recall was scored in the Cermak series of experiments by the number of correct words given aloud during the 10-sec recall interval. Given that for one experimental condition Ss received a homophonic repetition of the preceding trial, there is no way of knowing from verbal report alone which of the two trials is beins recalled. Written recall seems necessary and was employed in the present experiment.

Further, the nature of the semantic component change on the repetition trial in the present experiment was greater than that which Cermak employed. Specifically, the semantic change consisted of shifting to a totally new class of material, namely, from words to consonants.

In this experiment the Brown-Peterson paradigm was employed. On a particular trial, the trigram B, K, T or its homophonic parallel BEE, KAY, TEA was presented. Several trials later, the trigram $B, K, T$ was administered, representing for one experimental group an exact repetition and for the other an acoustic but not semantic

*This research was supported in part by Grant GB-3360 from the National Science Foundation to the senior author.

$+R$ equests for reprints should be sent to Delos $D$. Wickens Department of Psychology, Ohio State University, Columbus, Ohio 43210. repetition. The questions being asked were (1) would positive transfer occur for one group on the repetition trial (Cermak, 1969) but not for the other, relative to nonrepetition control groups, or (2) would both profit equally from the repetition, also relative to nonrepetition control groups.

\section{METHOD}

\section{Subjects}

The Ss were 432 male and female students enrolled in elementary psychology at Ohio State University. Participation in this experiment constituted partial fulfillment of the course requirement. The $S s$ were assigned by order of appearance to the two experimental and to the two control groups, with $108 \mathrm{Ss}$ in each group. The $\mathrm{N}+1 \mathrm{~S}$ was not assigned to any group until there were N Ss in all groups. A S's data were included in the results only if subjective report and performance on the rehearsal-preventative task indicated nonrehearsal of the materials and if the materials were accurately perceived, as indicated by $S$ 's reading aloud of each target item.

\section{Materials and Apparatus}

Two types of target items were used, CCCs and word trigrams. The only restrictions imposed upon the formation of the CCC items were that, at least until after the critical trial (Trial 8), no letter be used more than once, all obviously meaningful letter combinations be avoided, and the three letters of each target item be as acoustically distinct as possible. The experimental word trigram (EXPw) was BEE, KAY, TEA, homophonic with the experimental consonant trigram (EXPc), B, K, T. The control word trigram (CONTw), ANT, FRAN, MILK, was matched with EXPw for taxonomic class and for frequency on the Battig and Montague norms (1969). The control consonants were $R, F, M$ (CONTc).

All materials were projected by a Kodak Carousel projector controlled by a Gerbrands tape timer onto a $2 \times 2 \mathrm{~m}$ screen located about $1.5 \mathrm{~m}$ in front of $\mathrm{Ss}$. The experimental room was illuminated by a $40-\mathrm{W}$ bulb.

\section{Procedure}

The method of presentation employed the Peterson and Peterson rehearsal-preventative technique (1959). Each trial consisted of the following: a ready signal, an asterisk which was presented for $2 \mathrm{sec}$, followed by a 2 -sec presentation of the target item. A 6 by 5 matrix of color names printed in different colors then appeared for $18 \mathrm{sec}$ (Stroop, 1935, cited in Underwood, 1966). The Stroop test served as the 
Table 1

Typical Sequence of 11 Trials Experienced by All Ss

\begin{tabular}{cccccccccccc}
\hline 1 & 2 & 3 & 4 & 5 & 6 & 7 & 8 & 9 & 10 & 11 \\
\hline EGG & M & HAIR & SIR & J & R & S & Critical & G & N & Repetition \\
LAW & Q & JOY & DOOR & X & V & L & Trial & R & P & Trial \\
SKY & H & ROAD & BAG & F & N & C & & H & F & (B, K, T) \\
\hline
\end{tabular}

rehearsal-preventative activity. The Stroop slide was replaced by a question mark cueing $S$ for written recall and remained on for $8 \mathrm{sec}$. The ITI was, therefore, $30 \mathrm{sec}$.

After $S$ was seated and given the $3 \times 5$ in. cards on which to write his answers, he was given the standard instructions for this type of situation and some experience with the Stroop test slides. He was also informed that letters and words would be used in the memory task.

As Ss were informed in the instructions, recall in the correct position was not required and added nothing to the maximum possible score of three for correctly recalled trigrams. A recall was counted as correct if it occuned within the 8-sec recall interval and if it was an exact reproduction of the target item (e.g., TEE was not an acceptable recall of TEA).

After the experimental session, each $\mathrm{S}$ was questioned as to his efforts to keep from rehearsing. The Ss in the EXPw condition were further asked if they noticed the homophonic property of BEE, KAY, TEA when it was first presented. Finally, both experimental groups were questioned as to their awareness of any repetition.

\section{Design}

The design included two experimental groups and two control groups, each $\mathrm{S}$ in every group receiving 11 trials. The treatment for each group differed only on the critical trial. As described previously, the experimental groups received either B, K, T (EXPc) or the homophonic correlate, BEE, KAY, TEA (EXPw). The control groups were presented with either R, F, M (CONTc) or ANT, FRAN, MILK (CONTw). The typical session with 11 trials is shown in Table 1.

The first four trials, which employed both word triads and a CCC triad, were introduced to accustom Ss to shifting class material so that the presentation of a word triad on the critical trial would not appear unusual to the EXPw group. Trial 11, referred to as the repetition trial, was the same for all groups. For the experimental groups, B, K, T constituted repetition, a partial and acoustical one for the BEE, KAY, TEA (EXPw) group, and an exact replication for the EXPc group. For both control groups Trial 11 constituted a nonrepetition. Order of presentation of Trials 5,6 , and 7 was counterbalanced across Ss to control for position effects, and each item of the trigram on the critical trial and on the repetition trial appeared in each position equally often for the same reason. For any one $S$ in an experimental condition, items on the critical trial and on the repetition trial were in the same acoustical sequence.

\section{RESULTS}

The percentage of correct responses on the critical trial, as well as on the preceding and on the subsequent trials, is graphically represented in Fig. 1.

\section{The Critical Trial}

A one-way analysis of variance on the performance scores of the two experimental groups and the two control groups on the critical trial was significant $[F(3,428)=5.39, \mathrm{p}<.005]$. To identify more precisely the source of the variance on the critical trial, multiple $t$ tests were conducted on the four comparisons. In sum, they indicated that the two word groups did not differ from each other, nor did the two consonant groups, but the word groups did excel the consonant groups. However, the performance of these two latter groups on the class shift is confounded by the taxonomic difference between their test items. It is possible that BEE, KAY, TEA is an easier memory load than B, K, T, so little further is made of this comparison.

\section{The Preceding and the Intervening Trials}

On the trial preceding the critical trial, the groups did not differ significantly from each other $[F(3,428)=1.28, p<.28]$. Performance on the two trials subsequent to the critical trial when all groups returned to the same material was relatively low and did not differ among the groups $[F(3,428)<1$ and $F(3,428)=2.12, \mathrm{p}<.10$, respectively] .

\section{The Repetition Trial}

The results of the one-way analysis of variance on the repetition trial was highly significant $[F(3,428)=18.61$, $\mathrm{p}<.001]$. The four group comparisons were again analyzed for significant differences with multiple $t$ tests.

The presentation of an exact repetition of $\mathrm{B}, \mathrm{K}, \mathrm{T}$ for the EXPc group resulted in performance that was significantly higher than the performance of the EXPw

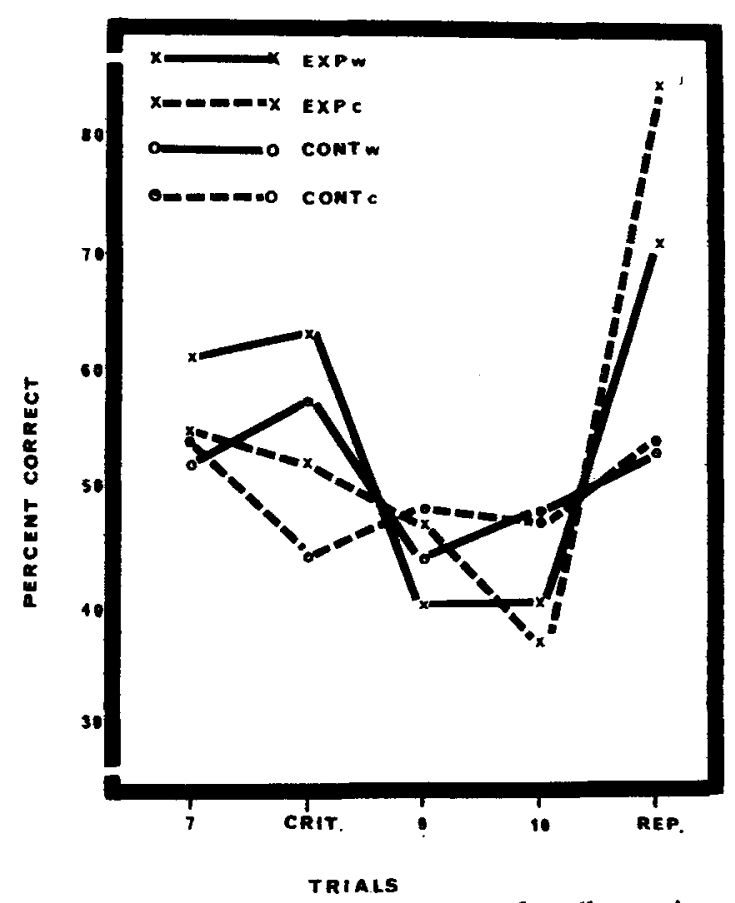

Fig. 1. Percentage of correct responses for all experimental and control groups. 
group that received the acoustically identical input on the critical trial, namely, BEE, KAY, TEA $[\mathrm{t}(214)=3.08, \mathrm{p}<.01]$. Furthermore, the comparisons between EXPw and CONTw [ $\mathrm{t}(214)=3.79, \mathrm{p}<.001]$ and between EXPc and CONTc $[t(214)=6.68$, $p<.001]$ were significant, indicating a facilitating effect of acoustical repetition over nonrepetition regardless of the semantic nature of the critical trial item. There was essentially no performance difference between the two nonrepetition groups $[\mathrm{t}(214)=.12]$.

\section{The Awareness of Homophones and Repetition}

The data of the postexperiment reports were broken down into those Ss who indicated an awareness of the experimental manipulation and those who did not. About half of the EXPc group indicated awareness of the repetition, while only $22 \%$ of the EXPw group fell into the aware category. The mean recall of those aware of the repetition regardless of experimental condition was about $87 \%$ and of those unaware was about $65 \%$.

A further breakdown of these data was done for the EXPw group, wherein another category of awareness could be identified, namely, awareness at the time of the critical trial that the words were homophonic with some consonants. By far, many more EXPw Ss did not notice the homophonic property of their critical trial item $(70 \%)$ than did notice it $(30 \%)$. Mean recall on the critical trial for the aware Ss $(73 \%)$ was better than the mean recall $(61 \%)$ of those unaware. The potential meaning of these data will be examined in the Discussion. Because of considerable variation in $\mathrm{N}$ across these groups and because the data are only suggestive, no probability tests were made on them.

\section{DISCUSSION}

\section{Awareness and Performance}

It will be recalled that Ss who were aware of the experimental manipulation performed better on the repetition trial, and this finding would indicate that this awareness produced the better performance. To check this interpretation of the data, the performance of the aware and the unaware groups were compared on the three CCC trials preceding the critical trial, a period during which all groups had been treated alike. The group that was eventually to become aware of repetition had slightly better performance on these trials than did the Ss who were not to become aware, $62 \%$ as opposed to $57 \%$. This suggests some tendency for the Ss who were eventually to be aware of repetition to perform better than those who were not to become aware. This fact raises questions about accounting for differences in performance on the basis of the awareness factor. The to-be-aware Ss might simply have better memories, for whatever reason, and the tendency toward awareness of manipulations might not be the cause of the superior performance but a phenomenon associated with it.

As a further approach to the role of awareness in performance, the EXPw group was subdivided into four subgroups based upon the contingent relationships of being aware of the homophonic characteristic on the critical trial and being aware of the acoustic repetition on the repetition trial. The best performance on the repetition trial was obtained by the subgroup which stated no awareness of the homophonic relationship but was aware of the repetition trial, and the next best performance was obtained by the group which was aware of both. The other two groups were alike in their performance. Further combinations of the groups aware of one aspect of the experimental manipulation, independent of their awareness of the other, indicated that awareness of the homophonic relationship alone did not seem to affect subsequent performance on the repetition trial, but being aware of the repetition was clearly related to superior performance on that trial.

This finding seems somewhat opposed to what one might predict according to the Tulving and Thompson (1971) view, which emphasizes the importance of encoding of retrieval cues at the time of input if they are later to be effective in recall. One might expect that the coordinate encoding of the words as having letter sounds during critical trial input would be at least a sufficient condition for superior recall on the repetition trial, but this does not seem to have been the case. It is quite possible, however, that awareness does not necessarily reflect the nature of the retrieval cues encoded.

In contrast to awareness of homophonic relationships, awareness of repetition seems to be markedly related to proficiency of recall. Unfortunately, Ss were not queried as to when the repetition manipulation was first recognized-at input, during the retention interval, during recall, or afterward. Thus, its significance in relationship to performance cannot be determined unequivocally.

\section{Interpretation}

The results of the present experiment are in partial, but not complete, agreement with those of Cermak's research. The role of the acoustic component in the repetition effect is evident in both experiments, despite the fact that the repetition in the present experiment involved a change from the conceptual class of words to the conceptual class of consonants. His acoustic repetition, of course, remained within the same class of material-words.

However, the present experiment, unlike Cermak's Experiment II, gave evidence for a semantic (as well as an acoustic) type of encoding. This effect is demonstrated in two ways. First, critical trial performance on words was superior to the performance of the groups who remained with CCCs, possibly signifying a release from PI effects due to a shift in class of materials (Reutener, 1972). Second, and this is the more significant point, the performances of the two experimental groups were not alike on the repetition trial. The performance of the exact repetition group 
excelled the performance of the acoustic (homophonic) repetition group. Had only a single feature been encoded, namely, the acoustic feature, the two groups should not have differed. The fact that they do can be accounted for by assuming that the two attributes were encoded on both the critical and repetition trials; however, the exact repetition group received both a semantic and an acoustic repetition, while the acoustic (homophonic) repetition group was given only an acoustic repetition. Cermak proposed that the brief input and immediate demand of the subtraction task did not allow Ss time to encode at a level deeper than the acoustic one, but the present experiment indicates otherwise. $^{2}$

The data of the present experiment are consistent with and supportive of the view that the encoding of and the memory for a verbal event consists of a collection of attributes (Bower, 1967; Underwood, 1969; Wickens, 1970). Just how the dual attributes of the exact repetition group operate to produce higher recall than the single attribute of the acoustic (homophonic) repetition group we do not know (Howell, 1973), but the multiple component conception of the memory trace itself seems to be required by the data.

\section{REFERENCES}

Battig, W. F., \& Montague, W. E. Category norms for verbal items in 56 categories: A replication and extension of the Connecticut category norms. Journal of Experimental Psychology Monograph, 1969, 80, (3).
Bower, G. A multicomponent theory of the memory trace. In $\mathrm{K}$. W. Spence and J. T. Spence (Eds.), The psychology of learning and motivation. New York: Academic Press, 1967.

Cermak, L. Repetition and encoding in short-term memory. Journal of Experimental Psychology, 1969, 82, 321-326.

Cermak. L. S. Proactive facilitation in short-term memory. Jourmal of Experimental Psychology, 1970, 85, 305-310.

Howell, W. S. Representation of frequency in memory. Psychological Bulletin, 1973, 80, 44-53.

Peterson, L. R., \& Peterson, M. J. Short-term retention of individual verbal items. Journal of Experimental Psychology, $1959,54,157-173$.

Reutener, D. B. Background, symbolic, and class shift in short-term memory. Journal of Experimental Psychology, $1972,93,90-94$

Tulving, E., \& Thompson, D. M. Retrieval processes in recognition mem ory: Effects of associative context. Journal of Experimental Psychology, 1971, 87, 116-124.

Underwood, B. J. Attributes of memory. Psychological Review, $1969,76,559-573$.

Underwood, B. J. Experimental psychology. 2nd ed. New York: Appleton-Century-Crofts, 1966.

Wickens, D. D. Encoding categories of words, Psychological Review, 1970, 77, 1-15.

\section{NOTES}

1. This statement would seem to be an overgeneralization. Cermak did not find a facilitation if the repetition was in the form of synonyms or antonyms, suggesting an absence of a semantic effect. This question will be considered further in the Discussion after the results of the present experiment have been presented.

2. Cermak, in his Experiment II where four trials intervened between the word triad and its homonym did not find any facilitating effect of the repetition. In the present experiment, with two intervening trials, the facilitating effect of acoustic repetition is massive and it is unclear how the acoustic trace could so fade over two more trials as to completely wipe out a repetition effect.

(Received for publication August 21, 1973; revision received February $6,1974$. 